OPEN ACCESS

Edited by:

Agnieszka Swiatecka-Urban, University of Pittsburgh School of Medicine, USA

Reviewed by:

Rachel Lennon,

University of Manchester, UK

R. Morrison Hurley,

University of British Columbia,

Canada

*Correspondence:

Kimberly Jean Reidy

kreidy@montefiore.org

Specialty section:

This article was submitted

to Pediatric Nephrology,

a section of the journal

Frontiers in Pediatrics

Received: 06 July 2015

Accepted: 06 May 2016

Published: 25 May 2016

Citation:

Hjorten R, Anwar Z and Reidy KJ

(2016) Long-term Outcomes of Childhood Onset

Nephrotic Syndrome.

Front. Pediatr. 4:53.

doi: 10.3389/fped.2016.00053

\section{Long-term Outcomes of Childhood Onset Nephrotic Syndrome}

\author{
Rebecca Hjorten, Zohra Anwar and Kimberly Jean Reidy* \\ Pediatrics Nephrology, Children's Hospital at Montefiore, Albert Einstein College of Medicine, Bronx, NY, USA
}

There are limited studies on long-term outcomes of childhood onset nephrotic syndrome (NS). A majority of children with NS have steroid-sensitive nephrotic syndrome (SSNS). Steroid-resistant nephrotic syndrome (SRNS) is associated with a high risk of developing end-stage renal disease. Biomarkers and analysis of genetic mutations may provide new information for prognosis in SRNS. Frequently relapsing and steroid-dependent NS is associated with long-term complications, including dyslipidemia, cataracts, osteoporosis and fractures, obesity, impaired growth, and infertility. Long-term complications of SSNS are likely to be under-recognized. There remain many gaps in our knowledge of long-term outcomes of childhood NS, and further study is indicated.

Keywords: nephrotic syndrome, children, pediatric, outcomes, genetics, focal glomerulosclerosis,
minimal-change disease

\section{INTRODUCTION}

Nephrotic syndrome (NS) is characterized by proteinuria, edema, hypoalbuminemia, and hyperlipidemia. The seminal studies of childhood onset NS were performed in the 1970s, in the International Study of Kidney Disease in Children (ISKDC) $(1,2)$. The ISKDC studies established the most likely pathologic diagnoses of childhood NS, as biopsies were performed at presentation in all 127 patients. Overall, the most common diagnosis $(n=95 / 127)$ was minimal-change disease (MCD), which was present in $94 \%$ of the children with steroid-sensitive nephrotic syndrome (SSNS) (1). In steroidresistant nephritic syndrome (SRNS), focal glomerulosclerosis (FSGS) was the most common histopathologic lesion (1). The ISKDC established that the majority of children with NS (80\%) respond to corticosteroid treatment $(1,2)$. Thus, the ISKDC established the paradigm of treating all children presenting with NS with corticosteroids and only performing biopsies in steroid resistant patients (2).

Since the ISKDC, the majority of studies looking at outcomes classified patients by response to corticosteroids or other therapy and by NS relapse. The least severe course with SSNS is associated with few or no relapses. More complicated are those with SSNS with frequent relapses (FR $=>2$ relapses over a 6 -month or $>3$ over a 12 -month period) or steroid dependence $(\mathrm{SD}=$ relapses during treatment or within 2 weeks of stopping corticosteroids) (3). Some patients with initial steroid response develop SRNS (late non-responders) and others present with SRNS. Finally, there are the most severe cases of NS that are both corticosteroid and other treatment resistant. Long-term renal-related complications of childhood NS would include NS relapse in adulthood, hypertension, chronic kidney disease (CKD), and end-stage renal disease (ESRD). Long-term non-renal complications include complications of corticosteroids and other immunosuppressant medications, including effects on growth, bone health, fertility, and risk for malignancy. An additional consideration are psychosocial issues associated with NS. As with many chronic diseases, NS can represent a barrier to attaining educational degrees and employment and/or developing stable relationships/marriage. Indeed, a quality-of-life (QOL) survey of children with NS in the National Institutes of Health Focal 
Segmental Glomerulosclerosis (NIH FSGS) clinical trial revealed that children with SRNS had poor QOL scores similar to children on dialysis (4).

Here, we will review the current data on long-term NS outcomes, potential new predictors of treatment and renal outcomes, and gaps in our knowledge that warrant further investigation.

\section{OUTCOMES IN SRNS}

It is clear that the worst outcomes occur in SRNS, with 34-64\% progressing to ESRD within 10 years of diagnosis (5-8). The majority of SRNS patients are treated with second-line agents, such as calcineurin inhibitors and other immunosuppressant medications. There is a highly variable response, which may depend upon the population studied. For example, studies of calcineurin inhibitors report divergent response rates of between 25 and 75\% in children with SRNS (9). This variability in response to calcineurin inhibitors likely reflects in part differences dependent on the underlying histopathology of the SRNS, with MCD more likely to respond than FSGS. Other factors, such as race or ethnicity of the population being studied, may also affect likelihood of response (10). In particular, AfricanAmerican and Hispanic children with FSGS have poorer outcomes, with one study demonstrating $50 \%$ progress to ESRD within 3 years $(11,12)$. What is clear is that response to any therapy is a major prognostic factor (13). Abeyagunawardena et al. examined 10-year outcomes of 66 children with SRNS. Response to therapy was associated with $90 \%$ renal survival, while almost $50 \%$ with failure to respond to therapy had progressed to ESRD (13). Response to second-line immunosuppressant therapy and risk of progression may differ in children who initially respond to therapy, but then become non-responsive (late non-responders). Straatmann et al. demonstrated that up to $87 \%$ of late non-responders in a multicenter study initially responded to a calcineurin inhibitor (14). However, long term, $31 \%$ of the cohort became non-responsive, and had decreased renal function and increased progression to ESRD compared to those that remained treatment responsive (14).

\section{BIOMARKERS TO PREDICT RESPONSE TO THERAPY}

One of the largest areas of research has been the search for soluble factors that may be predictive of treatment response and may also serve as targets for future therapies. This interest was partly spurred due to studies showing that serum from patients with FSGS can induce proteinuria in rats and increase the glomerular permeability of isolated glomeruli (15). In addition, plasmapheresis has been able to induce remission in some patients with recurrent FSGS post transplant $(16,17)$.

One circulating factor that has been studied is the soluble urokinase plasminogen activator (suPAR). Wei et al. showed in a study that 94 children with FSGS and 70 adults and children with FSGS had elevated levels of suPAR when compared with healthy controls (18). Peng et al. then showed, in a group of 176 children with idiopathic NS followed for approximately 30 months, that
suPAR levels were able to predict steroid resistance (19). However, these results have not been widely reproducible, questioning the role of suPAR to distinguish FSGS from other glomerular diseases (20-22). For example, Sinha et al. in a cross-sectional cohort study of 83 healthy pediatric controls versus 469 patients with NS, 138 of which had SSNS, was not able to show an association of suPAR levels with either SSNS versus SRNS. In the same study, suPAR levels were not significantly associated with the diagnosis of FSGS (22). This study demonstrated that suPAR had an inverse correlation with glomerular filtration rate, and some have proposed it may be a predictor of renal progression $(22,23)$.

Other investigators have looked to evidence of immune activation to predict response to immunosuppressive treatment. One study of 26 children with idiopathic SSNS that were followed for less than a year showed a differential pattern of regulatory Th1 and Th2 cells in patients in remission versus in relapse (24). Another study of 46 children with NS demonstrated that T-cell glucocorticoid receptor expression was higher in patients with NS responsive to steroid therapy and in patients with MCD, when compared to patients with FSGS (25). In one study of 17 patients with MCD and 22 with FSGS, urinary CD80 (present on antigen-presenting cells and podocytes) was able to distinguish MCD from FSGS. Another investigator determined that the urinary CD80 level associated with disease remission $(26,27)$. In a search for novel, yet unrecognized, markers of both steroid response and disease progression, investigators have used unbiased approaches to examine gene expression, the serum and urine proteome, and the metabolome (28-30). One group took serum from blood of 33 children with idiopathic SSNS at presentation, in remission while on medication, and in remission once medication was stopped. Evaluating serum peptide levels at all time points, they identified a novel marker, apolipoprotein AII. The levels of apolipoprotein AII correlated with degree of proteinuria at presentation and decreased with remission (31).

All these studies are limited by small numbers of patients and most are single-center studies. Poor reproducibility has plagued efforts to identify biomarkers in NS $(32,33)$. Thus, newly available large cohorts of NS patients, such as Podonet (34), NEPTUNE (35), and Cure GN that include well-characterized pediatric patient populations of NS are critical for discovery and validation of new biomarkers.

\section{GENETIC FACTORS IN PREDICTING OUTCOME IN NS}

One of the new factors that may predict response to therapy and renal outcomes are genetic variants of NS. Genetic mutations are most likely to be identified in congenital nephrotic syndrome (CNS). Mutations in NPHS1, NPHS2, LAMB2, and WT-1 were identified in two-thirds of a largely European cohort of 89 infants with NS under the age of 1 (36). The overall average age of ESRD was 5.6 years. While the numbers were small and many outcomes were not known, patients with NPHS1 mutations had ESRD at an average age of 4.6 years, whereas those with NPHS2 mutations had ESRD at an average age of 7.4 years (36). It is possible these differences could be explained by differences in clinical course 
and management of congenital NS (e.g., nephrectomies), rather than the genetic basis of disease. However, it suggests that additional studies should address whether specific genetic mutations correlate with outcomes in early onset NS.

There are well over 40 genetic mutations associated with FSGS, and new mutations continue to be identified (37). A single-gene mutation may be identified in up to $29 \%$ of patients with SRNS onset prior to age 25 (38). Patients with genetic mutations are less likely to respond to immunosuppressant therapy and more likely to develop ESRD (39). One of the largest studies by Buscher et al. examined renal outcomes of at 10-year follow-up of 231 children in a European cohort with SRNS. For those presenting after 3 months of age, $58 \%$ children with SRNS associated with genetic mutations had progressed to ESRD, versus 29\% with SRNS and no genetic mutation identified (39). Recently, genetic variants in APOL1 were identified as risk factors for renal disease in people of African descent. Carrying two copies of APOL1 coding variants (G1 and G2) is a risk factor for hypertensive nephropathy, lupus nephropathy, FSGS, and HIV nephropathy (40). Recent analysis of the FSGS Clinical Trial, a NIH supported randomized controlled trial comparing MMF to cyclosporine in children and young adults (41), demonstrated that $67-72 \%$ of 94 patients of African descent in the study harbored two copies of the APOL1 risk variants, and they were more likely to progress to ESRD, with $40 \%$ reaching ESRD within approximately 8 years (42). Of note, APOL1 risk variants did not associate with response to therapy, although a small percentage responded to either therapy (41). Many genetic analyses, to date, have focused on largely European and homogeneous populations; the cohorts of NEPTUNE (35, 43) and CureGN provide an opportunity to understand the contribution of gene-gene and gene-environmental interactions in modulating long-term outcomes.

Recently, two genes have been identified associated with treatment sensitive NS. Epithelial membrane protein 2 (EMP2) was identified in familial SSNS (44). While only a few patients were identified, the majority had no renal failure after over 20 years of follow-up (44). Overall, one can be optimistic that, in the future, identification of specific genetic mutations may help guide therapy and provide prognostic information to families.

\section{LONG-TERM COMPLICATIONS OF STEROID-SENSITIVE NEPHROTIC SYNDROME ARE LIKELY UNDER-RECOGNIZED}

There is increasing focus on a life-course approach to optimizing health outcomes, with recognition that exposures in childhood establish the risk for adult-onset disease (45). The vast majority of children will have SSNS and MCD, which is thought to have benign long-term outcomes. However, recent studies have suggested that other conditions that were thought to be benign, such as congenital solitary kidneys, are associated in increased risk of hypertension and ESRD in adulthood (46). The increased risk of ESRD required more than 30 years to manifest, and thus was unlikely to be detected without a concerted effort to study outcomes in these patients (46). Potential long-term complications of SSNS are likely to be under-recognized, as patients are often lost to follow-up.

\section{OUTCOMES IN SSNS}

There are a handful of studies looking at long-term outcomes of childhood onset SSNS (Table 1). All studies include either exclusively or mostly FR/SD NS patients.

\section{RISK OF RELAPSE AS AN ADULT}

An early study by Trompeter et al. suggested that only $5 \%$ of children will have persistent relapses as adults (47). However, several recent studies suggest that FRNS is common, and relapses may persist into adulthood. Esfahani et al. examined the course of NS of over 200 children from Iran with follow-up between 5 and 20 years (52). Eighty-three percent experienced relapses in childhood and over $50 \%$ required additional immunosuppressive treatment, likely indicating FR/SD NS. Less than half the cohort sustained a remission for more than 3 years. Similarly, Ishikura et al. performed 10-year follow-up of a randomized controlled trial of cyclosporine for FR/SDNS in Japan. Fifty percent continued to relapse and remain on immunosuppressives in adulthood (50).

TABLE 1 | Long-term complications of childhood SSNS.

\begin{tabular}{|c|c|c|c|}
\hline & Complication & Reported prevalence & Comment \\
\hline \multirow[t]{3}{*}{ Renal } & Relapses in adulthood & $5-40 \%(47,48)$ & $\begin{array}{l}\text { Higher risk with early onset, more } \\
\text { frequent relapses in childhood }\end{array}$ \\
\hline & Decreased GFR/ESRD & $<1 \%$ at 20 -year follow-up (48) & \\
\hline & Hypertension & $6-46 \%(49,50)$ & Highest in FRNS with adult relapses \\
\hline \multirow[t]{7}{*}{ Immunosuppression-related } & Overweight/obesity & $8-23 \%(50,51)$ & \\
\hline & Growth failure & $8-16 \%(48,50)$ & \\
\hline & Osteoporosis & $13-63 \%(49,50)$ & Highest in FRNS with adult relapses \\
\hline & Fractures & $20 \%(51)$ & \\
\hline & Cataracts & $6-20 \%(49,50)$ & Highest in FRNS with adult relapses \\
\hline & Infertility & Up to $75-94 \%(49,51)$ & Highest with cytotoxic therapy \\
\hline & Malignancy & Unknown & \\
\hline \multirow[t]{2}{*}{ Psychosocial } & Educational status and employment & $\begin{array}{l}<10 \% \text { failure to complete high school and }<45 \% \\
\text { unemployed ( } 51)\end{array}$ & Single-center study \\
\hline & Marital status/stable relationships & $<40 \%$ unmarried or not in stable relationship (51) & Single-center study \\
\hline
\end{tabular}


Fakhouri et al. studied 102/117 children admitted with SSNS in France using mailed questionnaires or phone calls to patients and/or their parents or attending physicians (48). More than $40 \%$ of the patients relapsed in adulthood (48). Younger age of NS onset, second-line immunosuppressant therapy, and more severe disease in childhood were associated with increased risk of relapse in adulthood. However, relapse rate in the first 6 months of disease was not predictive of adult relapses. Kabuki et al. also examined age of presentation effects on risk of relapse in 60 patients diagnosed with NS before age 10 in Japan with over 10 years follow-up (53). The majority (51/60) patients were relapse-free over 3 years. Early presentation (between age 1 and 3.9 years) was associated with more relapses and a longer interval between onset of NS and long-term remission. Conversely, older onset (after age 7 years) was associated with less active disease at 10 years follow-up.

Skrzypczyk et al. examined outcomes of $61 / 118$ children with NS in Poland using a written questionnaire (51). Over $90 \%$ were SSNS and only 30\% FRNS. However, 77\% required second-line immunosuppressive therapy in addition to steroids. The patients had particularly benign courses in that all patients achieved remission and had normal renal function at the age of 18. Still $16 \%$ relapsed in adulthood, and risk of relapse as adult was associated with relapses as a child.

One of the longest follow-up studies was by Ruth et al. on 42 children with NS from Switzerland with a median follow-up of 22 years. Thirty-three percent of patients had relapses as adults. Number of relapses during childhood and adolescence and requirement for second-line therapy were risks for relapses in adulthood (54).

\section{RENAL AND NON-RENAL COMPLICATIONS}

Several of these studies examined long-term complications of immunosuppression. Ishikura et al. identified that on 10-year follow-up of exclusively FR/SDNS patients, a substantial number had short stature $(13 \%)$, osteoporosis $(13 \%)$, obesity $(8 \%)$, cataracts (6\%), and hypertension (6\%) (50). Fakhouri et al. obtained information in their SSNS patients with $40 \%$ rate of relapse in adulthood (48). Of them, $7 \%$ had hypertension, and 1 out of the 102 patients had developed ESRD. The most common complications were likely long-term side effects of corticosteroids: $16 \%$ had short stature, $20 \%$ were overweight or obese, and $63 \%$ had osteoporosis.

One of the few direct assessments of long-term outcomes was performed by Kyrieleis et al. in 15 adult patients from the Netherlands with history of childhood onset FRNS who were still relapsing as adults (mean follow-up 24 years). Forty-six percent of patients had hypertension. Dual-energy X-ray absorptiometry identified osteoporosis in one-third of patients. Ophthalmologic examination identified cataracts in $3 / 15(20 \%)$ of the patients. Six out of eight $(75 \%)$ had abnormal semen examination with oligozoospermia, reduced sperm motility, and teratozoospermia.

The study of 61 patients with childhood NS from Poland by Skrzypczyk et al. demonstrated a substantial number of immunosuppressant-related complications. Sixteen percent were hypertensive, $23 \%$ were overweight, and $4.9 \%$ obese. Almost
$20 \%$ had bone fractures and $8 \%$ had short stature (height $<$ third percentile). Childlessness was more common (94\%) in those treated with cytotoxic agents versus those not treated with cytotoxic agents. No increased risk of malignancy, infection, or cardiovascular events was detected.

Skrzypczyk et al. was one of the only studies to examine longterm psychosocial impact of NS as a chronic disease (51). In their follow-up study, $60.7 \%$ patients were in a steady relationship/ married, $40.9 \%$ pursued higher education, and only $6.6 \%$ did not complete a high school (secondary) education. At the time of the study, 55.7\% patients reported active employment.

Of note, none of studies that examined GFR observed a change $(49,51)$. The study with the longest follow-up ( 22 years) by Ruth et al. identified no effects on growth, obesity, or GFR, but did identify an effect on fertility (54). Only 8/42 patients had children, and cytotoxic therapy was associated with childlessness (54).

Nephrotic syndrome leads to endothelial dysfunction in children (55) and engenders a risk for artherosclerosis in adults $(56,57)$. In one study of 30 patients with childhood onset SSNS, dysregulation of lipids, including increased total cholesterol, lowdensity lipoprotein cholesterol, and homocysteine were persistent on follow-up at 4-15 years after completion of steroids (57).

\section{GAPS IN OUR KNOWLEDGE OF LONG-TERM OUTCOMES OF SSNS}

The majority of the above studies are retrospective chart reviews or utilized surveys, with the inherent biases of those types of study design. Virtually, all studies lack a control population, which is relevant for outcomes, such as obesity and hypertension, which may be common in the adult population. Often they represent a single-center experience and have small numbers. Even the largest studies report outcomes from countries with homogenous populations, with limitations in their generalizability to ethnically diverse populations. Finally, the average length of follow-up in most studies was approximately 10 years, well short of the 30-year follow-up required to identify effects of a solitary kidney on ESRD outcomes (46).

It seems possible that, as with other conditions previously thought to be entirely benign, SSNS may engender increased risk of hypertension, atherosclerosis, CKD, and ESRD in adulthood (Table 2). In addition, there are insufficient studies of patient-reported outcomes, including QOL assessments. There are limited data on implications of childhood NS on educational attainment, employment, and marital status. Better understanding of potential adverse consequences may allow for interventions targeting improvement of both patient-reported and psychosocial outcomes. Our lack of knowledge limits effective transition of children with NS to adult providers. Those with few or no relapses are likely not to follow-up or to follow-up rarely with a pediatric nephrologist as they approach adulthood. An adult nephrologist is unlikely to follow these patients, as the majority will not have renal impairment at entry into adulthood. So the major question becomes how and when to communicate the potential for long-term issues with adult providers. One study in Japan demonstrated that the majority of practitioners had no transition plan in place for children with SSNS (58). 


\section{Gaps in knowledge}

\section{Life-course effects of childhood NS}

Are there risks of SSNS after 30 years? Are patients with childhood onset NS at higher risk of hypertension, $\mathrm{CKD}$, and ESRD?

\section{Genetic factors and biomarkers}

Can permeability factors or other biomarkers enable personalized approach to treatment? Can screening for genetic mutations or APOL1 variants in childhood onset NS stratify those children at highest risk for hypertension and renal disease in adulthood?

\section{Psychosocial impact and patient-reported outcomes}

Quality of life is significantly affected in childhood onset NS, particularly with severe disease. What is the effect on patient-reported outcomes? What is the long-term effect on educational status, employment and marital/stable relationships and are there interventions to improve outcomes?

\section{Transition into adulthood}

(1) When should children with NS receive counseling about potential risks in adulthood?

(2) How will adult providers be made aware of potential for complications in adults with a history of childhood NS?

(3) Are screenings for artherosclerosis, osteoporosis, cataracts, infertility, and/or malignancy indicated?

(4) What is the optimal transition plan for children with SSNS as they enter adulthood?

\section{Opportunities to address}

Registries of childhood onset nephrotic syndrome cNEPTUNE (pediatric cohort of incident nephrotic syndrome patients)

Multicenter collaborative cohorts of pediatric onset NS

Multicenter collaborative cohorts of pediatric onset NS

Registries and multicenter collaborative cohorts of pediatric onset NS
Patient registries and follow-up of pediatric cohorts, such as cNEPTUNE (incident children with NS), may help provide answers to these questions.

\section{CONCLUSION}

Underlying renal pathology, genetic factors, and ethnicity likely modulate response to treatment and progression of ESKD. Wellcharacterized and prospectively followed cohorts provide an exciting opportunity to improve our understanding of the ability of biomarkers and genetics to predict outcomes. Many of the long-term complications of childhood SSNS can be attributed to immunosuppressant therapy. Long-term effects on endothelium

\section{REFERENCES}

1. Nephrotic syndrome in children: prediction of histopathology from clinical and laboratory characteristics at time of diagnosis. A report of the International Study of Kidney Disease in Children. Kidney Int (1978) 13(2):159-65.

2. The primary nephrotic syndrome in children. Identification of patients with minimal change nephrotic syndrome from initial response to prednisone. A report of the International Study of Kidney Disease in Children. J Pediatr (1981) 98(4):561-4.

3. Kaku Y, Ohtsuka Y, Komatsu Y, Ohta T, Nagai T, Kaito H, et al. Clinical practice guideline for pediatric idiopathic nephrotic syndrome 2013: general therapy. Clin Exp Nephrol (2015) 19(1):34-53. doi:10.1007/s10157-014-1031-9

4. Gipson DS, Trachtman H, Kaskel FJ, Radeva MK, Gassman J, Greene TH, et al. Clinical trials treating focal segmental glomerulosclerosis should measure patient quality of life. Kidney Int (2011) 79(6):678-85. doi:10.1038/ki.2010.485

5. Cattran DC, Rao P. Long-term outcome in children and adults with classic focal segmental glomerulosclerosis. Am J Kidney Dis (1998) 32(1):72-9. doi:10.1053/ajkd.1998.v32.pm9669427

6. Paik KH, Lee BH, Cho HY, Kang HG, Ha IS, Cheong HI, et al. Primary focal segmental glomerular sclerosis in children: clinical course and prognosis. Pediatr Nephrol (2007) 22(3):389-95. doi:10.1007/s00467-006-0301-5

7. Mekahli D, Liutkus A, Ranchin B, Yu A, Bessenay L, Girardin E, et al. Long-term outcome of idiopathic steroid-resistant nephrotic syndrome: a multicenter study. Pediatr Nephrol (2009) 24(8):1525-32. doi:10.1007/s00467-009-1138-5

8. Zagury A, Oliveira AL, Montalvao JA, Novaes RH, Sa VM, Moraes CA, et al. Steroid-resistant idiopathic nephrotic syndrome in children: long-term and renal function are likely understudied. Long-term studies of childhood onset SSNS patients, perhaps by patient registries, are needed to understand the true risk of the disease to adult health.

\section{AUTHOR CONTRIBUTIONS}

All authors listed have made substantial, direct, and intellectual contribution to the work and approved it for publication.

\section{FUNDING}

RH is supported by NIH NIDDK T32 DK007110. KR received support from NIH NIDDK K08 DK091507 and R03 DK105242.

follow-up and risk factors for end-stage renal disease. J Bras Nefrol (2013) 35(3):191-9. doi:10.5935/0101-2800.20130031

9. Hodson EM, Willis NS, Craig JC. Interventions for idiopathic steroid-resistant nephrotic syndrome in children. Cochrane Database Syst Rev (2010) (11):CD003594. doi:10.1002/14651858.CD003594.pub4

10. Andreoli SP. Racial and ethnic differences in the incidence and progression of focal segmental glomerulosclerosis in children. Adv Ren Replace Ther (2004) 11(1):105-9. doi:10.1053/j.arrt.2003.10.015

11. Ingulli E, Tejani A. Racial differences in the incidence and renal outcome of idiopathic focal segmental glomerulosclerosis in children. Pediatr Nephrol (1991) 5(4):393-7. doi:10.1007/BF01453661

12. Sorof JM, Hawkins EP, Brewer ED, Boydstun II, Kale AS, Powell DR. Age and ethnicity affect the risk and outcome of focal segmental glomerulosclerosis. Pediatr Nephrol (1998) 12(9):764-8. doi:10.1007/s004670050542

13. Abeyagunawardena AS, Sebire NJ, Risdon RA, Dillon MJ, Rees L, Van't Hoff W, et al. Predictors of long-term outcome of children with idiopathic focal segmental glomerulosclerosis. Pediatr Nephrol (2007) 22(2):215-21. doi:10.1007/ s00467-006-0264-6

14. Straatmann C, Ayoob R, Gbadegesin R, Gibson K, Rheault MN, Srivastava T, et al. Treatment outcome of late steroid-resistant nephrotic syndrome: a study by the Midwest Pediatric Nephrology Consortium. Pediatr Nephrol (2013) 28(8):1235-41. doi:10.1007/s00467-013-2483-y

15. Savin VJ, Sharma R, Sharma M, McCarthy ET, Swan SK, Ellis E, et al. Circulating factor associated with increased glomerular permeability to albumin in recurrent focal segmental glomerulosclerosis. N Engl J Med (1996) 334(14):878-83. doi:10.1056/nejm199604043341402 
16. Dall'Amico R, Ghiggeri G, Carraro M, Artero M, Ghio L, Zamorani E, et al. Prediction and treatment of recurrent focal segmental glomerulosclerosis after renal transplantation in children. Am J Kidney Dis (1999) 34(6):1048-55. doi:10.1016/s0272-6386(99)70010-7

17. Mahesh S, Del Rio M, Feuerstein D, Greenstein S, Schechner R, Tellis V, et al. Demographics and response to therapeutic plasma exchange in pediatric renal transplantation for focal glomerulosclerosis: a single center experience. Pediatr Transplant (2008) 12(6):682-8. doi:10.1111/j.1399-3046.2007.00880.x

18. Wei C, Trachtman H, Li J, Dong C, Friedman AL, Gassman JJ, et al. Circulating suPAR in two cohorts of primary FSGS. J Am Soc Nephrol (2012) 23(12):20519. doi:10.1681/asn.2012030302

19. Peng Z, Mao J, Chen X, Cai F, Gu W, Fu H, et al. Serum suPAR levels help differentiate steroid resistance from steroid-sensitive nephrotic syndrome in children. Pediatr Nephrol (2015) 30(2):301-7. doi:10.1007/s00467-0142892-6

20. Bock ME, Price HE, Gallon L, Langman CB. Serum soluble urokinase-type plasminogen activator receptor levels and idiopathic FSGS in children: a single-center report. Clin J Am Soc Nephrol (2013) 8(8):1304-11. doi:10.2215/ cjn. 07680712

21. Meijers B, Maas RJ, Sprangers B, Claes K, Poesen R, Bammens B, et al. The soluble urokinase receptor is not a clinical marker for focal segmental glomerulosclerosis. Kidney Int (2014) 85(3):636-40. doi:10.1038/ki.2013.505

22. Sinha A, Bajpai J, Saini S, Bhatia D, Gupta A, Puraswani M, et al. Serumsoluble urokinase receptor levels do not distinguish focal segmental glomerulosclerosis from other causes of nephrotic syndrome in children. Kidney Int (2014) 85(3):649-58. doi:10.1038/ki.2013.546

23. Jolanta S, Jacek Z, Anna B, Maria LS, Michal N, Danuta ON. Circulating suPAR as a biomarker of disease severity in children with proteinuric glomerulonephritis. Minerva Pediatr (2016).

24. Prasad N, Jaiswal AK, Agarwal V, Yadav B, Sharma RK, Rai M, et al. Differential alteration in peripheral T-regulatory and T-effector cells with change in P-glycoprotein expression in Childhood Nephrotic Syndrome: a longitudinal study. Cytokine (2015) 72(2):190-6. doi:10.1016/j.cyto.2014. 12.028

25. Zahran AM, Aly SS, Elsayh KI, Badawy A, Gamal Y. Glucocorticoid receptors expression and histopathological types in children with nephrotic syndrome. Ren Fail (2014) 36(7):1067-72. doi:10.3109/0886022x.2014.917936

26. Garin EH, Diaz LN, Mu W, Wasserfall C, Araya C, Segal M, et al. Urinary CD80 excretion increases in idiopathic minimal-change disease. J Am Soc Nephrol (2009) 20(2):260-6. doi:10.1681/asn.2007080836

27. Ishimoto $\mathrm{T}$, Cara-Fuentes $\mathrm{G}$, Wang $\mathrm{H}$, Shimada $\mathrm{M}$, Wasserfall $\mathrm{CH}$, Winter WE, et al. Serum from minimal change patients in relapse increases CD80 expression in cultured podocytes. Pediatr Nephrol (2013) 28(9):1803-12. doi:10.1007/s00467-013-2498-4

28. Wickman L, Afshinnia F, Wang SQ, Yang Y, Wang F, Chowdhury M, et al. Urine podocyte mRNAs, proteinuria, and progression in human glomerular diseases. J Am Soc Nephrol (2013) 24(12):2081-95. doi:10.1681/asn.2013020173

29. Erkan E, Zhao X, Setchell K, Devarajan P. Distinct urinary lipid profile in children with focal segmental glomerulosclerosis. Pediatr Nephrol (2016) 31(4):581-8. doi:10.1007/s00467-015-3239-7

30. Suresh CP, Saha A, Kaur M, Kumar R, Dubey NK, Basak T, et al. Differentially expressed urinary biomarkers in children with idiopathic nephrotic syndrome. Clin Exp Nephrol (2016) 20(2):273-83. doi:10.1007/s10157-0151162-7

31. Kanai T, Yamagata T, Ito T, Odaka J, Saito T, Aoyagi J, et al. Apolipoprotein AII levels are associated with the UP/UCr levels in idiopathic steroid-sensitive nephrotic syndrome. Clin Exp Nephrol (2015) 19(1):107-13. doi:10.1007/ s10157-014-0957-2

32. Spinale JM, Mariani LH, Kapoor S, Zhang J, Weyant R, Song PX, et al. A reassessment of soluble urokinase-type plasminogen activator receptor in glomerular disease. Kidney Int (2015) 87(3):564-74. doi:10.1038/ki. 2014.346

33. Novelli R, Gagliardini E, Ruggiero B, Benigni A, Remuzzi G. Any value of podocyte B7-1 as a biomarker in human MCD and FSGS? Am J Physiol Renal Physiol (2016) 310(5):F335-41. doi:10.1152/ajprenal.00510.2015

34. Trautmann A, Bodria M, Ozaltin F, Gheisari A, Melk A, Azocar M, et al. Spectrum of steroid-resistant and congenital nephrotic syndrome in children: the PodoNet registry cohort. Clin J Am Soc Nephrol (2015) 10(4):592-600. doi:10.2215/cjn.06260614

35. Gadegbeku CA, Gipson DS, Holzman LB, Ojo AO, Song PX, Barisoni L, et al. Design of the Nephrotic Syndrome Study Network (NEPTUNE) to evaluate primary glomerular nephropathy by a multidisciplinary approach. Kidney Int (2013) 83(4):749-56. doi:10.1038/ki.2012.428

36. Hinkes BG, Mucha B, Vlangos CN, Gbadegesin R, Liu J, Hasselbacher K, et al. Nephrotic syndrome in the first year of life: two thirds of cases are caused by mutations in 4 genes (NPHS1, NPHS2, WT1, and LAMB2). Pediatrics (2007) 119(4):e907-19. doi:10.1542/peds.2006-2164

37. Akchurin O, Reidy KJ. Genetic causes of proteinuria and nephrotic syndrome: impact on podocyte pathobiology. Pediatr Nephrol (2015) 30(2):221-33. doi:10.1007/s00467-014-2753-3

38. Sadowski CE, Lovric S, Ashraf S, Pabst WL, Gee HY, Kohl S, et al. A single-gene cause in $29.5 \%$ of cases of steroid-resistant nephrotic syndrome. J Am Soc Nephrol (2015) 26(6):1279-89. doi:10.1681/asn.2014050489

39. Buscher AK, Kranz B, Buscher R, Hildebrandt F, Dworniczak B, Pennekamp $\mathrm{P}$, et al. Immunosuppression and renal outcome in congenital and pediatric steroid-resistant nephrotic syndrome. Clin J Am Soc Nephrol (2010) 5(11):2075-84. doi:10.2215/cjn.01190210

40. Genovese G, Friedman DJ, Pollak MR. APOL1 variants and kidney disease in people of recent African ancestry. Nat Rev Nephrol (2013) 9(4):240-4. doi:10.1038/nrneph.2013.34

41. Gipson DS, Trachtman H, Kaskel FJ, Greene TH, Radeva MK, Gassman JJ, et al. Clinical trial of focal segmental glomerulosclerosis in children and young adults. Kidney Int (2011) 80(8):868-78. doi:10.1038/ki.2011.195

42. Kopp JB, Winkler CA, Zhao X, Radeva MK, Gassman JJ, D'Agati VD, et al. Clinical features and histology of apolipoprotein L1-associated nephropathy in the FSGS clinical trial. J Am Soc Nephrol (2015) 26(6):1443-8. doi:10.1681/ asn.2013111242

43. Sampson MG, Robertson CC, Martini S, Mariani LH, Lemley KV, Gillies CE, et al. Integrative genomics identifies novel associations with APOL1 risk genotypes in Black NEPTUNE subjects. J Am Soc Nephrol (2016) 27(3):814-23. doi:10.1681/asn.2014111131

44. Gee HY, Ashraf S, Wan X, Vega-Warner V, Esteve-Rudd J, Lovric S, et al. Mutations in EMP2 cause childhood-onset nephrotic syndrome. Am J Hum Genet (2014) 94(6):884-90. doi:10.1016/j.ajhg.2014.04.010

45. Brophy PD, Shoham DA, Charlton JR, Carmody J, Reidy KJ, Harshman L, et al. Early-life course socioeconomic factors and chronic kidney disease. $A d v$ Chronic Kidney Dis (2015) 22(1):16-23. doi:10.1053/j.ackd.2014.06.006

46. Sanna-Cherchi S, Ravani P, Corbani V, Parodi S, Haupt R, Piaggio G, et al. Renal outcome in patients with congenital anomalies of the kidney and urinary tract. Kidney Int (2009) 76(5):528-33. doi:10.1038/ki.2009.220

47. Trompeter RS, Lloyd BW, Hicks J, White RH, Cameron JS. Long-term outcome for children with minimal-change nephrotic syndrome. Lancet (1985) 1(8425):368-70. doi:10.1016/S0140-6736(85)91387-X

48. Fakhouri F, Bocquet N, Taupin P, Presne C, Gagnadoux MF, Landais P, et al. Steroid-sensitive nephrotic syndrome: from childhood to adulthood. Am J Kidney Dis (2003) 41(3):550-7. doi:10.1053/ajkd.2003.50116

49. Kyrieleis HA, Lowik MM, Pronk I, Cruysberg HR, Kremer JA, Oyen WJ, et al. Long-term outcome of biopsy-proven, frequently relapsing minimal-change nephrotic syndrome in children. Clin J Am Soc Nephrol (2009) 4(10):1593-600. doi:10.2215/cjn.05691108

50. Ishikura K, Yoshikawa N, Nakazato H, Sasaki S, Nakanishi K, Matsuyama T, et al. Morbidity in children with frequently relapsing nephrosis: 10-year follow-up of a randomized controlled trial. Pediatr Nephrol (2015) 30(3):459-68. doi:10.1007/s00467-014-2955-8

51. Skrzypczyk P, Panczyk-Tomaszewska M, Roszkowska-Blaim M, Wawer Z, Bienias B, Zajgzkowska M, et al. Long-term outcomes in idiopathic nephrotic syndrome: from childhood to adulthood. Clin Nephrol (2014) 81(3):166-73. doi: $10.5414 / \mathrm{cn} 108044$

52. Esfahani ST, Madani A, Asgharian F, Ataei N, Roohi A, Moghtaderi M, et al. Clinical course and outcome of children with steroid-sensitive nephrotic syndrome. Pediatr Nephrol (2011) 26(7):1089-93. doi:10.1007/s00467-0111837-6

53. Kabuki N, Okugawa T, Hayakawa $H$, Tomizawa S, Kasahara T, Uchiyama M. Influence of age at onset on the outcome of steroid-sensitive 
nephrotic syndrome. Pediatr Nephrol (1998) 12(6):467-70. doi:10.1007/ s004670050489

54. Ruth EM, Kemper MJ, Leumann EP, Laube GF, Neuhaus TJ. Children with steroid-sensitive nephrotic syndrome come of age: long-term outcome. J Pediatr (2005) 147(2):202-7. doi:10.1016/j.jpeds.2005.03.050

55. Rahul I, Krishnamurthy S, Satheesh S, Biswal N, Bobby Z, Lakshminarayanan S. Brachial artery flow-mediated dilatation and carotid intima medial thickness in pediatric nephrotic syndrome: a cross-sectional case-control study. Clin Exp Nephrol (2015) 19(1):125-32. doi:10.1007/s10157-014-0958-1

56. Ordonez JD, Hiatt RA, Killebrew EJ, Fireman BH. The increased risk of coronary heart disease associated with nephrotic syndrome. Kidney Int (1993) 44(3):638-42. doi:10.1038/ki.1993.292

57. Kniazewska MH, Obuchowicz AK, Wielkoszynski T, Zmudzinska-Kitczak J, Urban K, Marek M, et al. Atherosclerosis risk factors in young patients formerly treated for idiopathic nephrotic syndrome. Pediatr Nephrol (2009) 24(3):549-54. doi:10.1007/s00467-008-1029-1

58. Honda M, Iijima K, Ishikura K, Kaneko K. The problem of transition from pediatric to adult healthcare in patients with steroid-sensitive nephrotic syndrome (SSNS): a survey of the experts. Clin Exp Nephrol (2014) 18(6):93943. doi:10.1007/s10157-014-0941-x

Conflict of Interest Statement: KR is site-PI of a Questcor supported research study of patients with nephrotic syndrome. She receives no direct reimbursement from Questcor.

The remaining coauthors declare that the research was conducted in the absence of any commercial or financial relationships that could be construed as a potential conflict of interest.

Copyright $\odot 2016$ Hjorten, Anwar and Reidy. This is an open-access article distributed under the terms of the Creative Commons Attribution License (CC BY). The use, distribution or reproduction in other forums is permitted, provided the original author(s) or licensor are credited and that the original publication in this journal is cited, in accordance with accepted academic practice. No use, distribution or reproduction is permitted which does not comply with these terms. 